\title{
Semiflexible Thermotropic Liquid-Crystalline Polymers: The Characterization of a Polyester-Polyether
}

\author{
G. Galli, E. Chiellini,${ }^{\dagger}$ G. Torquati, ${ }^{*}$ \\ R. CACIUfFo, ${ }^{*}$ S. MElone, ${ }^{*}$ \\ and B. GALLOT** \\ Dipartimento di Chimica e Chimica Industriale, Università di Pisa, \\ 56100 Pisa, Italy \\ * Dipartimento di Scienza dei Materiali e della Terra, \\ Università di Ancona, 60131 Ancona, Italy \\ ** Centre de Biophysique Moléculaire, CNRS, \\ 45071 Orléans Cedex 2, France
}

(Received September 19, 1988)

\begin{abstract}
The liquid crystal behavior of the thermotropic polyester derived from $\left(4,4^{\prime}\right.$ terephthaloyldioxy)dibenzoic acid and tetraethylene glycol was studied by differential scanning calorimetry, polarizing microscopy, and X-ray diffraction. The polymer sample exhibits the phase sequence isotropic-nematic-smectic A-smectic E-crystal, with decreasing temperature. Attention was devoted to the optical textures of the mesophases, as compared to those of low molar mass mesogens, and unusual high strength singularities were detected in the schlieren texture of the nematic phase.
KEY WORDS Liquid-Crystalline Polymers / Thermotropic Polyesters / Liquid-Crystalline Polymorphism/ Smectic Mesophases/ Schlieren Textures /

The thermotropic liquid-crystalline behavior of main chain polymers comprising alternating mesogenic units and flexible spacers is well established and attracts ever increasing interest. The great majority of such polymers presents only one mesophase, typically nematic (or cholesteric), but smectic phases have also been observed, including ordered smectic $B^{1}, E^{2}, G^{3}$ or $H^{4}$ phases. A few examples are known of mesophase polymorphism $^{5}$, this feature being in marked contrast with what is most commonly observed in low molecular weight mesogens.

In a previous paper ${ }^{6}$ some of us reported on the synthesis and characterization of the thermotropic properties of a class of polyesters derived from 4,4'-(terephthaloyldioxy)dibenzoic acid (HTH) and ethylene (or propylene) glycol ethers of different lengths:<smiles>CC(=O)c1ccc(OC(=O)c2ccc(OC(=O)c3ccc(C(=O)OCCCOO)cc3)cc2)cc1</smiles>

Polymer samples having $n=2,3$, or 4 displayed two different enantiotropic liquidcrystalline phases, the lower temperature mesophase being a provisionally unidentified smectic phase and the higher temperature mesophase being recognized as nematic. ${ }^{6}$ In the same context, unusual textural behaviors were observed in such polymers, especially at the mesophase-mesophase transition. All these features have stimulated further investigation and accordingly the polyester sample of that class with $n=4$, here designated as HTH/TEG, was freshly prepared from HTH diacid chloride and tetraethylene glycol (TEG) and

\footnotetext{
† To whom correspondence should be addressed.
} 
studied by means of differential scanning calorimetry, polarizing microscopy and X-ray diffraction. In the present paper we report a detailed investigation of the thermotropic mesophase behavior of $\mathrm{HTH} / \mathrm{TEG}$, with particular reference to polymorphism in the liquid crystal state. Unusual textures with high strength defects were also detected and are briefly presented.

\section{EXPERIMENTAL}

\section{Synthesis of the Polymer}

Polyester HTH/TEG was prepared according to the reported procedure ${ }^{6.7}$ by reacting stoichiometric amounts of bischloroformyl 4,4'-(terephthaloyldioxy)dibenzoate ( $\mathrm{Cl}$ $\mathrm{HTHCl}$ ) and tetraethylene glycol (TEG) in 1,2-dichloroethane solution at $70^{\circ} \mathrm{C}$ in the presence of excess pyridine. Yield: $90 \%$. The polymer sample is characterized by an intrinsic viscosity value of $0.20 \mathrm{dl} / \mathrm{g}$ in trifluoroacetic acid at $30^{\circ} \mathrm{C}$, and $\bar{M}_{w}=8000, \overline{M W D}=1.8$ to which an average degree of polymerization of approximately $10-12$ should correspond ${ }^{7}$.

\section{Physico-Chemical Characterizations}

Gel permeation chromatography measurements were carried out with a Perkin-Elmer 2/2 liquid chromatograph equipped with Shodex A802/S and A803/S columns and a Perkin-Elmer LC75 spectrophotometric detector (detection wavelength $\lambda=280 \mathrm{~nm}$ ). Monodisperse polystyrene standard samples $\left(\bar{M}_{v}=500,2100,4000,9000\right.$, and 83000) were used for calibration. Integral and differential thermogravimetry analyses were performed under dry nitrogen flow with a Mettler TG50 thermobalance at a heating rate of $20^{\circ} \mathrm{C}$ $\min ^{-1}$.

Differential scanning calorimetry (DSC) analysis was carried out under nitrogen flow on polymer samples $(7-12 \mathrm{mg}$ ) with a PerkinElmer DSC2 calorimeter equipped with a scanning autozero. A heating/cooling rate of

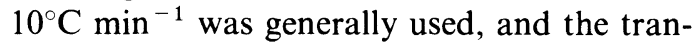

sition temperatures were taken as corresponding to the maximum of the enthalpic peaks. Indium and tin standards were used for temperature calibration. Enthalpy changes were evaluated by means of indium reference samples. The melting behavior of the polymer was studied using different heating rates $(5,10$, 20 , and $40^{\circ} \mathrm{C} \mathrm{min}^{-1}$ ) on melt-crystallized samples prepared by cooling from the isotropic melt at $20^{\circ} \mathrm{C} \mathrm{min}^{-1}$. Texture observations were performed on polymer films between glass slides without any previous treatment by means of a Reichert Polyvar microscope equipped with a Mettler FP52 heating stage.

$\mathrm{X}$-Ray diffraction experiments were carried out with a conventional X-ray powder diffractometer. The divergence of the primary beam impinging on the sample was $8^{\prime}$. The generator-to-sample distance was $18 \mathrm{~cm}$ and the sample-to-detector distance was $20 \mathrm{~cm}$. The sample had a thickness of about $1.5 \mathrm{~mm}$ and was sandwiched between two thin aluminum sheets fixed to a circular hole in an aluminum matrix with a diameter of $1 \mathrm{~cm}$. XRay diffraction diagrams were also recorded between 20 and $200^{\circ} \mathrm{C}$ with a Guinier-type focusing camera equipped with a bent quartz monochromator giving a linear collimation of strictly monochromatic X-rays. The Ni-filtered $\mathrm{Cu}-K_{\alpha}$ radiation $(\lambda=1.54 \AA)$ was used in all cases. The degree of crystallinity of the polymer samples was evaluated from the diffraction pattern in the $2 \theta=15-30^{\circ}$ region.

\section{RESULTS AND DISCUSSION}

\section{Thermal Analysis}

The HTH/TEG polyester was investigated by thermogravimetric analysis between room temperature and $650^{\circ} \mathrm{C}$ and found to be thermally stable up to $340^{\circ} \mathrm{C}$, a $80 \%$ weight loss being detected between 350 and $620^{\circ} \mathrm{C}$.

The DSC heating curves of virgin $\mathrm{HTH} /$ TEG samples are characterized by the presence of two main endothermic transitions (Figure 1A). The first endotherm is somewhat 


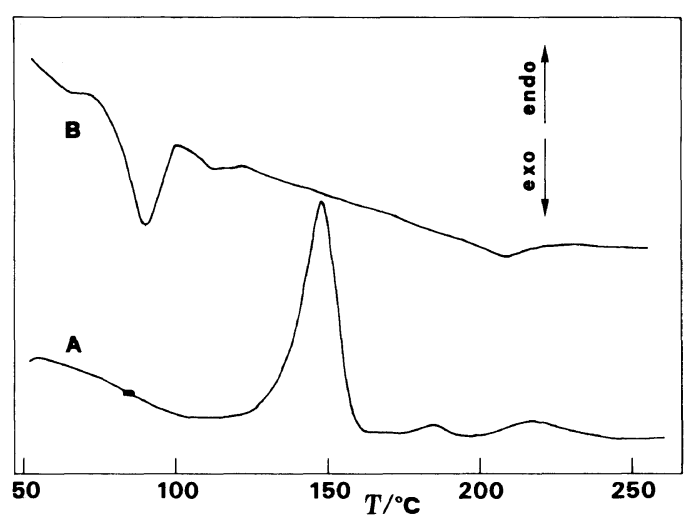

Figure 1. First heating (A) and cooling (B) cycle of polyester $\mathrm{HTH} / \mathrm{TEG}$ (scanning rate $10^{\circ} \mathrm{Cmin}^{-1}$ ).

broadened on the low temperature side and corresponds to the melting process. The maximum is centered at $148^{\circ} \mathrm{C}$ and the apparent enthalpy is $19 \mathrm{~kJ} \mathrm{~mol}^{-1}$. The second transition corresponding to the isotropization transition $\left(T_{\mathrm{i}}=217^{\circ} \mathrm{C}\right)$ is rather broad, indicative of the existence of a wide liquid crystal/isotropic liquid biphasic region, in agreement with polarization microscopy observations. The relevant enthalpy is $2.4 \mathrm{~kJ} \mathrm{~mol}^{-1}$, which is consistent with the isotropization of a nematic phase. An intermediate, weak endotherm $\left(\Delta H=1.1 \mathrm{~kJ} \mathrm{~mol}^{-1}\right)$ is also present at $182^{\circ} \mathrm{C}$ due to a mesophase-mesophase transition. The glass transition temperature had been previously found to be located at $47^{\circ} \mathrm{C}$ by dynamic-mechanical measurements on HTH/ TEG samples quenched from the isotropic state. ${ }^{8}$ On cooling (Figure 1B) the minimum of the isotropic-mesophase exotherm is located at $211^{\circ} \mathrm{C}$, this process showing a very limited degree of supercooling $\left(6^{\circ} \mathrm{C}\right)$. A weak and shallow signal is centered at $180^{\circ} \mathrm{C}$ due to a mesophase-mesophase transition, while crystallization occurs at $90^{\circ} \mathrm{C}$. Such a supercooling $\left(-60^{\circ} \mathrm{C}\right)$ allows us to detect an additional exotherm $\left(\Delta H=1.5 \mathrm{~kJ} \mathrm{~mol}^{-1}\right)$ at $110^{\circ} \mathrm{C}$ ascribable to the onset of a new smectic mesophase. The observed thermal behavior is in general agreement with the previously reported data, ${ }^{6}$ even though small differences in the transition

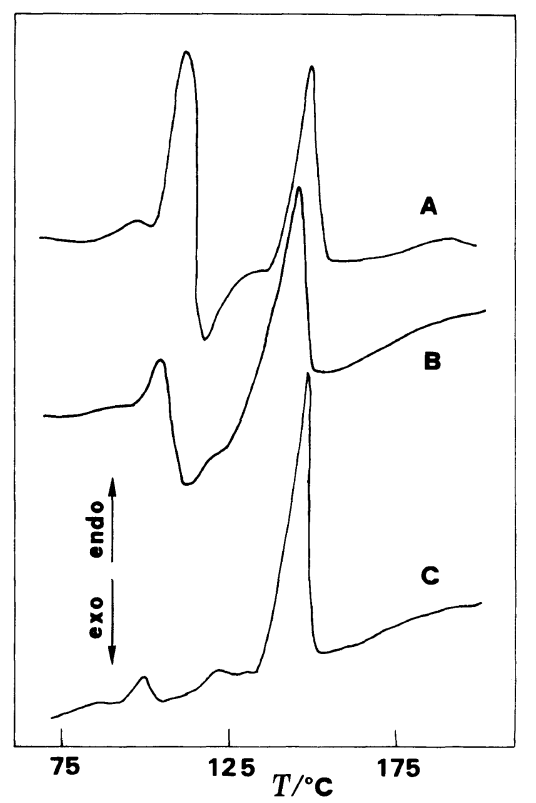

Figure 2. Melting endotherms of HTH/TEG samples as obtained under different conditions: (A) meltcrystallized and heated at $20^{\circ} \mathrm{Cmin}^{-1}$; (B) meltcrystallized and heated at $5^{\circ} \mathrm{Cmin}^{-1}$; (C) meltcrystallized and annealed at $109^{\circ} \mathrm{C}$ for $30 \mathrm{~min}$ and heated at $20^{\circ} \mathrm{C} \mathrm{min}^{-1}$. In all cases the cooling rate from the isotropic melt had been of $20^{\circ} \mathrm{C} \mathrm{min}^{-1}$.

temperatures may be due to differences in the molecular weight and polydispersity of the polymer samples.

Successive heating curves of melt-crystallized samples present the same mesophase transitions, in spite of a rather complex melting behavior (Figure 2). This last is characterized by two distinct endothermic peaks at about $109^{\circ} \mathrm{C}$ and $148^{\circ} \mathrm{C}$. An intermediate broad exotherm extends from $110^{\circ} \mathrm{C}$ to $130^{\circ} \mathrm{C}$, due to a cold-crystallization process. This is an unusually wide range of temperature and in fact makes it possible to observe melt flow at the microscope. The relative magnitude and maximum temperature of the two endotherms depend markedly on the thermal history, and we studied by DSC melt-crystallized samples by using different scanning rates and annealing treatments. In going from a heating rate of $40^{\circ} \mathrm{C} \mathrm{min}^{-1}$ to a rate of $5^{\circ} \mathrm{Cmin}^{-1}$, the in- 
Table I. Melting enthalpies of polyester HTH/TEG samples, as obtained under different experimental conditions

\begin{tabular}{|c|c|c|c|c|}
\hline \multirow{2}{*}{$\operatorname{Run}^{a}$} & Heating rate & $\Delta H_{1}^{\mathrm{b}}$ & $\Delta H_{\mathrm{II}}^{\mathrm{c}}$ & \multirow{2}{*}{$\Delta H_{\mathrm{I}} / \Delta H_{\mathrm{I}}$} \\
\hline & ${ }^{\circ} \mathrm{C} \min ^{-1}$ & $\mathrm{Jg}^{-1}$ & $\mathrm{Jg}^{-1}$ & \\
\hline 1 & 40 & 15.9 & 5.0 & 3.2 \\
\hline 2 & 20 & 13.8 & 9.6 & 1.4 \\
\hline 3 & 10 & 11.7 & 13.4 & 0.9 \\
\hline 4 & 5 & 3.3 & 17.6 & 0.2 \\
\hline 5 & 20 & 1.8 & 18.8 & 0.1 \\
\hline 6 & 20 & $\mathrm{nd}^{\mathrm{d}}$ & 19.2 & $\sim 0$ \\
\hline
\end{tabular}

a Runs 1-4, melt-crystallized sample (cooling rate $20^{\circ} \mathrm{Cmin}^{-1}$ ); runs 5 and 6 , melt-crystallized sample (cooling rate $20^{\circ} \mathrm{C} \mathrm{min}^{-1}$ ) and annealed for $30 \mathrm{~min}$ at $109^{\circ} \mathrm{C}$ and $116^{\circ} \mathrm{C}$, respectively.

b Enthalpy of the endotherm at about $109^{\circ} \mathrm{C}$.

c Enthalpy of the endotherm at about $148^{\circ} \mathrm{C}$.

d Not detectable, $\Delta H<0.4 \mathrm{~J} \mathrm{~g}^{-1}$.

tensity of the low temperature endotherm is greatly reduced relative to the high temperature one, and the ratio of respective enthalpies varies from 3.2 to 0.2 (Table I). On the contrary, the melting transition of samples annealed for $30 \mathrm{~min}$ at $109^{\circ} \mathrm{C}$ or at $116^{\circ} \mathrm{C}$ practically presents one single peak at $148^{\circ} \mathrm{C}$ (Table I) and at the same time the crystallization exotherm is completely vanished (Figure 2C). These DSC results suggest that the overall melting process in the $\mathrm{HTH} / \mathrm{TEG}$ polyester arises from interconvertible crystalline forms through the first fusion followed by recrystallization and reorganization of the more defective form to a more sized and perfect, high melting modification, in agreement with X-ray data (see below). We have also shown ${ }^{9}$ that the complex melting behavior of an isothermally crystallized polyester derived from the same $\mathrm{HTH}$ mesogenic core and decamethylenediol can originate from crystalline structures with significant differences in their crystal morphologies.

\section{Polarization Microscopy}

Upon heating, the polymer mesophase between 160 and $200^{\circ} \mathrm{C}$ displays a highly dense

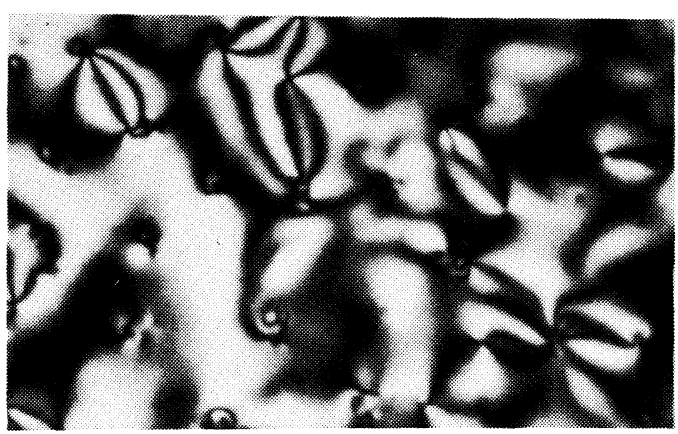

(A)

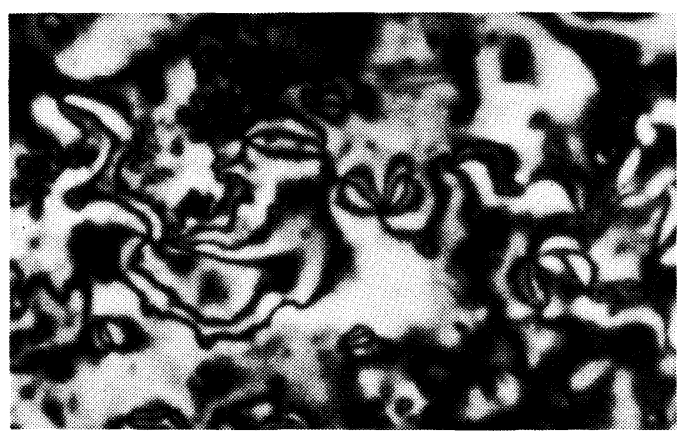

(B)

Figure 3. Nematic schlieren textures with high strength singularities: (A) at $217^{\circ} \mathrm{C}$ and (B) at $208^{\circ} \mathrm{C}$ (original magnification $320 \times$ ).

texture with no distinctive features. More familiar schlieren textures are only observed above $200^{\circ} \mathrm{C}$. Isotropic liquid is clearly visible at about $220^{\circ} \mathrm{C}$ and is completely developed at $240^{\circ} \mathrm{C}$. On cooling from the isotropic melt, a mesophase starts to nucleate at $225^{\circ} \mathrm{C}$, and then grows exhibiting a fine nematic schlieren pattern. Typical disclinations ${ }^{10}$ of strength $|S|=1$ and $|S|=1 / 2$ are commonly observed. On aging, some defects of integral strength are unstable and break into pairs of defects of half-integral order. Similar results have been previously reported for other thermotropic polyesters, ${ }^{11.12}$ and also are in agreement with theoretical predictions discussed for low molar mass mesogens. ${ }^{13}$ However, we could detect disclinations of even higher strength $|S|=2$, those seem to be quite persistent, at least for a few hours (Figure 3). Recently, we have given 
the first report on high strength defects in liquid-crystalline polymers, ${ }^{14}$ within the investigation of the metastable nematic phase of a poly(ester- $\beta$-sulphide) derived from azoxybis(1,4-phenylene)diacrylate and 1,5-pentanedithiol. At that time, the occurrence of such defects in polymers was thought to be confined to a peculiar case, but the present polymer system offers one more example and seems to point towards a more general incidence of similar phenomena in liquidcrystalline polymers. It may be observed that high strength defects are still rather rare even in low molar mass mesogens and limited to, e.g., mixtures of the lyotropic system disodiumcromoglycate-water-ethylene glycol ( $15: 60: 25$ by weight) with MBBA or 4-cyano4 '-pentyl-biphenyl, ${ }^{15}$ or mixtures of nonmesomorphic leucoquinizarin with various nematogenic 4-cyanophenyl-4- $n$-alkylbenzoates. $^{16,17}$

On further cooling below $200^{\circ} \mathrm{C}$, a focalconic texture with fans appears according to the onset of a smectic phase (Figure 4). Large areas have a strong tendency to orient homeotropically, and the observed pattern reminds those typical of the smectic A phase of low molecular weight mesogens. At $\sim 125^{\circ} \mathrm{C}$ the fan-shaped texture begins to develop striations, as an indication of the transition to another, more ordered smectic phase. After annealing at $120^{\circ} \mathrm{C}$, the fans appear slightly chequered with concentric arcs running across them (Figure 5) and partially remain as a paramorphotic texture frozen in the solid down to room temperature. Based on polarizing microscope observations, ${ }^{18}$ we suggest the low temperature phase to be a smectic E phase. The occurrence of a smectic E phase has also been proposed' by means of optical observations of analogus textural behavior in terphenyl-containing polyesters. ${ }^{2}$

\section{$X$-Ray Diffraction}

The X-ray diffraction patterns recorded on polyester $\mathrm{HTH} / \mathrm{TEG}$ at different temperatures

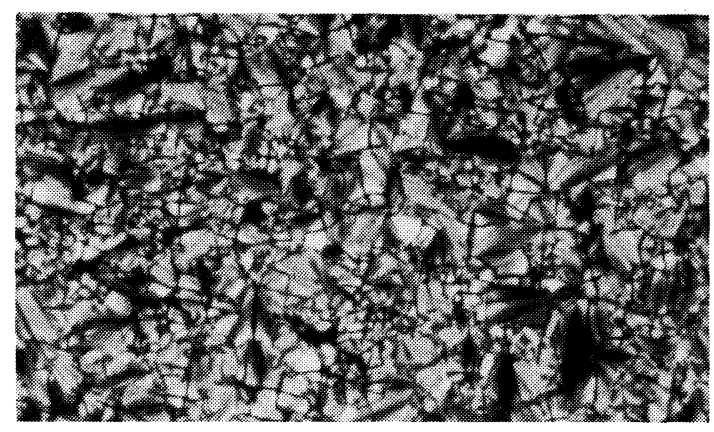

Figure 4. Focal-conic texture with fans of the smectic A phase at $147^{\circ} \mathrm{C}$ (original magnification $320 \times$ ).

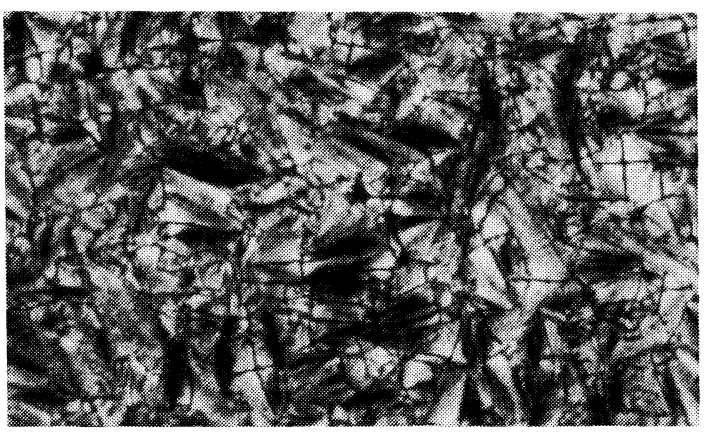

Figure 5. Fan texture with concentric arcs of the smectic E phase at $109^{\circ} \mathrm{C}$ (original magnification $230 \times$ ).

in the range $25-220^{\circ} \mathrm{C}$ are shown in Figures 6 and 7. At room temperature the investigated compound is characterized by a definite degree of crystallinity $\left(\chi_{c} \simeq 45 \%\right)$, as roughly deduced from the shape of the corresponding diffraction spectrum (Figure 6A). On increasing the temperature above $90^{\circ} \mathrm{C}$, a continuous decrease of the small angle diffuse scattering is observed with a concomitant appearance of a not completely resolved diffraction peak whose angular position corresponds to a Bragg layer periodicity $d$ of $34 \pm 0.5 \AA$ (Figure $6 \mathrm{~B})$. This distance can be related to the length of the repeating unit in its most extended alltrans conformation ( $L=33 \pm 1 \AA$ ). However, a small change also seems to take place in the lateral order of the molecular arrangement, as can be inferred from the appearance of a new weak signal at $2 \theta=23.1^{\circ}$, which is better evidenced on films recorded with a focusing 


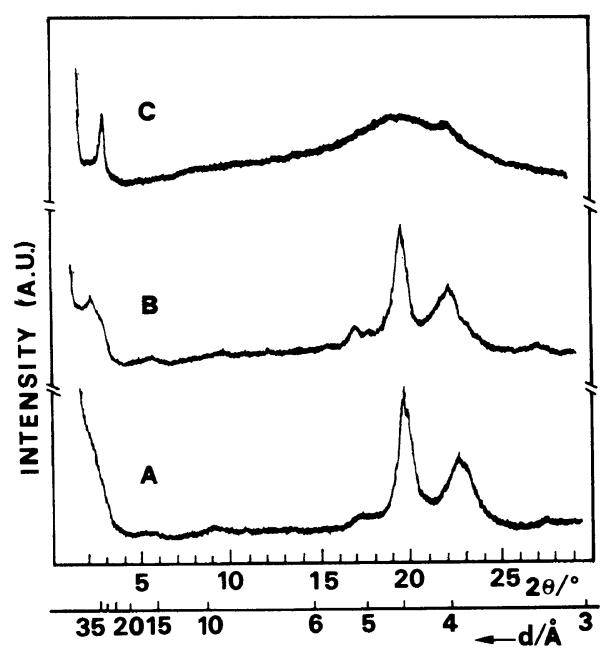

Figure 6. X-Ray diffraction patterns of polyester HTH/TEG with increasing temperature: (A) virgin sample at $25^{\circ} \mathrm{C}$; (B) crystalline at $130^{\circ} \mathrm{C}$; (C) ordered smectic phase at $175^{\circ} \mathrm{C}$.

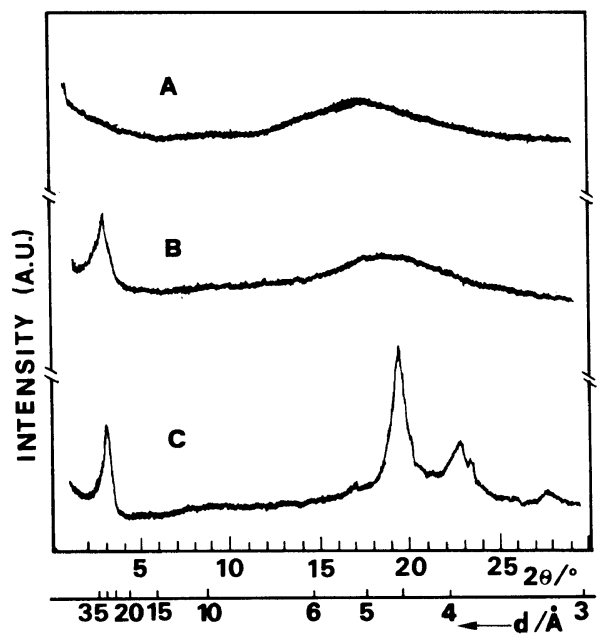

Figure 7. X-Ray diffraction patterns of polyester HTH/TEG with decreasing temperature: (A) nematic phase at $210^{\circ} \mathrm{C}$; (B) disordered smectic phase at $190^{\circ} \mathrm{C}$; (C) melt-crystallized at $25^{\circ} \mathrm{C}$.

camera. These findings qualitatively indicate a progressive increase of order that may be connected with the annealing of structural defects consequent to the increased segmental motion of the polymer chains above the glass transition temperature $\left(T_{\mathrm{g}} \simeq 47^{\circ} \mathrm{C}\right)$. At about $140^{\circ} \mathrm{C}$ a phase transition occurs accompanied

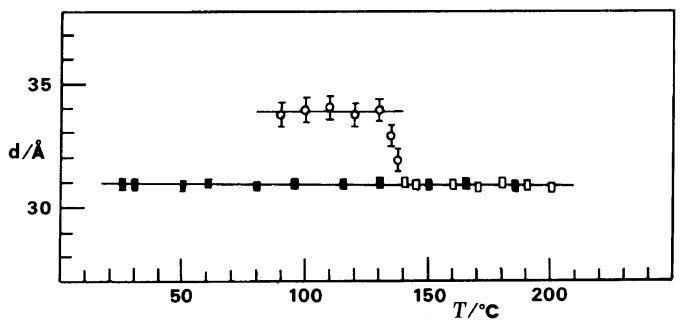

Figure 8. Variation of the interlayer distance $d$ of the smectic phase as function of temperature: $(O)$ heating of the virgin sample; $(\square)$ heating and ( $\square$ ) cooling of the melt-crystallized sample.

by marked changes in the intensity and position of the diffraction peaks. The interlayer distance is shortened from 34 to $31 \AA$ and then remains nearly unaffected by temperature between 145 and $200^{\circ} \mathrm{C}$ (Figure 8). The wide angle peaks corresponding to periodicities of 5.2, 4.6, and $3.9 \AA$ attenuate with increasing temperature up to $175^{\circ} \mathrm{C}$ (Figure 6C), and above this temperature coalesce in a broad signal associated to an average interchain distance $D \simeq 4.9 \AA$ (Figure 7B). These results can be interpreted assuming the existence between 145 and $175^{\circ} \mathrm{C}$ of an ordered smectic phase $\left(\mathrm{S}_{\mathrm{E}}\right)$ which transforms into a disordered smectic phase $\left(\mathrm{S}_{\mathrm{A}}\right)$ spanning up to $200^{\circ} \mathrm{C}$. Above this temperature, the diffraction pattern is consistent with the existence of a nematic mesophase, only presenting a very broad halo at wide angles (Figure 7A). On cooling, the transition nematic-smectic occurs at $200^{\circ} \mathrm{C}$, with no hysteresis phenomena. The scattering pattern characteristic of this smectic phase (Figure 7B) is preserved down to approximately $125^{\circ} \mathrm{C}$. At this temperature some peaks start to emerge from the wide angle halo. Apparently, a new more ordered smectic phase $\left(S_{E}\right)$ is formed, which cannot be fully investigated before complete crystallization takes place, in agreement with DSC and microscopy observations. The angular position of the signal corresponding to a layer thickness of $31 \AA$ remains practically unchanged in the melt-crystallized polymer down to room temperature $\left(\chi_{\mathrm{c}} \simeq 50 \%\right)$. 
It is established that crystalline poly(ethylene oxide) presents a distorted $7 / 2$ helix with a pitch length of $19.5 \AA,{ }^{19.20}$ and the TTG repeating sequence is the stable conformation even in solution ${ }^{21}$. According to these findings, one can evaluate a length of $31.1 \AA$ for the $\mathrm{HTH} / \mathrm{TEG}$ repeating unit, as observed for the crystal lattice of the melt-crystallized sample and for the interlayer spacing in the smectic phases between 145 and $200^{\circ} \mathrm{C}$. These arguments lend support to the occurrence of orthogonal smectic phases. However, due to the impossibility of performing X-ray experiments on oriented HTH/TEG samples, the existence of tilted smectic phases cannot be completely ruled out. It should be mentioned that the polyesters based on the same HTH mesogenic precursor and decamethylenediol or dodecamethylenediol, i.e., a spacer of equivalent length but different chemical nature from that used here, only exhibit a smectic phase, A or C. ${ }^{9,22}$

Moreover, the results obtained indicate that in the HTH/TEG polyester there exist two crystalline forms with crystal structures differing in the length of the unit-cell parameter. The first form, consistent with a fully extended conformation of the TEG spacer segment, appears to be metastable and remains frozen-in as the polymer is precipitated from solution. In the second form, as obtained by crystallization from the melt, the TEG spacer should adopt a stable TTG conformation.

\section{CONCLUSIONS}

The thermotropic liquid-crystalline polyester-polyether HTH/TEG presents, after thermal recycling and aging treatments, the phase sequence $\mathrm{K} \stackrel{148^{\circ} \mathrm{C}}{\longrightarrow} \mathrm{S}_{\mathrm{E}} \stackrel{175^{\circ} \mathrm{C}}{\longrightarrow} \mathrm{S}_{\mathrm{A}} \stackrel{200^{\circ} \mathrm{C}}{\longrightarrow} \mathrm{N}$ $\stackrel{217^{\circ} \mathrm{C}}{\longrightarrow}$ I. Two crystalline forms there also occur, depending upon the origin and thermal history of the sample. The mesomorphic polymorphism, that seems to be a common feature in several HTH-based polyesters consist- ing of a variety of spacer segments, ${ }^{5 \mathrm{~g}, 23}$ must be associated with the long, lath-like shape of the mesogenic core. It is, however, to stress once again the importance of the flexible spacer in defining not only the mesophase stability, but also its specific structures.

Acknowledgment. This work was partially supported from Progetti Bilaterali within the agreement between Italian CNR and French CNRS.

\section{REFERENCES}

1. A. Blumstein, K. N. Sivaramakrishnan, R. B. Blumstein, and S. B. Clough, Polymer, 23, 47 (1982).

2. L. Bosio, B. Fayolle, C. Friedrich, F. Laupetre, P. Meurisse, C. Noel, and J. Virlet, in "Liquid Crystals and Ordered Fluids," Vol. 4, A. C. Griffin and J. F. Johnson, Eds., Plenum, Press, New York, N. Y., 1984, p 401.

3. D. Guillon and A. Skoulios, Mol. Cryst. Liq. Cryst., Lett., 49, 119 (1978).

4. W. R. Krigbaum, J. Watanabe, and T. Ishikawa, Macromolecules, 16, 1271 (1983).

5. See for instance: a) E. Chiellini, G. Galli, C. Malanga, and N. Spassky, Polym. Bull. (Berlin), 9, 336 (1983); b) P. Meurisse, C. Noel, L. Monnerie, and B. Fayolle, Br. Polym. J., 13, 55 (1981); c) J. Watanabe and W. R. Krigbaum, Macromolecules, 18, 2288 (1985); d) T. D. Shaffer and V. Percec, J. Polym. Sci., Polym. Lett. Ed., 23, 185 (1985); e) C. Carfagna, A. Roviello, and A. Sirigu, Makromol. Chem., 187, 2123 (1986); f) J. M. W. Cowie and H. H. Wu, Polym. Bull. (Berlin), 16, 327 (1986); g) B. Gallot, G. Galli, and E. Chiellini, Makromol. Chem., Rapid Commun., 8, 417 (1987).

6. G. Galli, E. Chiellini, C. Ober, and R. W. Lenz, Makromol. Chem., 183, 2693 (1982).

7. E. Chiellini and G. Galli, Macromolecules, 18, 1652 (1985)

8. V. Frosini, S. dePetris, E. Chiellini, G. Galli, and R. W. Lenz, Mol. Cryst. Liq. Cryst., 98, 223 (1983).

9. M. Pracella, V. Frosini, G. Galli, and E. Chiellini, Mol. Cryst. Liq. Cryst., 113, 201 (1984).

10. D. Demus and L. Richter, "Textures of Liquid Crystals," Verlag Chemie, Weinheim, 1978.

11. C. Noel, F. Laupetre, C. Friedrich, B. Fayolle, and L. Bosio, Polymer, 25, 808 (1984).

12. G. Mazelet and M. Kleman, Polymer, 27, 714 (1986).

13. J. Nehring and A. Saupe, J. Chem. Soc., Faraday Trans. 2, 68, 1 (1972).

14. G. Galli, M. Laus, A. S. Angeloni, P. Ferruti, and E. Chiellini, Eur. Polym. J., 21, 727 (1985). 
15. H. Lee and M. M. Labes, Mol. Cryst. Liq. Cryst., Lett., 82, 192 (1982).

16. N. V. Madhusudana and R. Pratibha, Curr. Sci., 51, 877 (1982).

17. N. V. Madhusudana and R. Pratibha, Mol. Cryst. Liq. Cryst., 103, 31 (1983).

18. G. W. Gray and J. W. Goodby, "Smectic Liquid Crystals," Leonhard Hill, Glasgow, 1984.

19. H. Tadokoro, Y. Chatani, Y. Yoshirata, S. Tahara, and S. Murahashi, Makromol. Chem., 73, 109 (1964).

20. H. Tadokoro, Polymer, 25, 147 (1984).

21. P. J. Flory, "Statistical Mechanics of Chain Molecules," Wiley, New York, 1969.

22. C. Ober, J. I. Jin, and R. W. Lenz, Makromol. Chem., Rapid Commun., 4, 49 (1983).

23. E. Chiellini, G. Galli, S. Carrozzino, G. Torquati, and S. Melone, Mol. Cryst. Liq. Cryst., 146, 385 (1987). 